\title{
Mesothelioma Cells Escape Heat Stress by Upregulating Hsp40/Hsp70 Expression via Mitogen-Activated Protein Kinases
}

\author{
Michael Roth, ${ }^{1,2,3}$ Jun Zhong, ${ }^{2}$ Michael Tamm, ${ }^{2}$ and John Szilard ${ }^{1}$ \\ ${ }^{1}$ Molecular Medicine Research Group, The Woolcock Institute for Medical Research, University of Sydney, \\ 20 Missendon Road, Camperdown, NSW 2050, Australia \\ ${ }^{2}$ Pulmonary Cell Research, Department of Internal Medicine and Research, University Hospital Basel, Petersgraben 4, \\ CH-4031 Basel, Switzerland \\ ${ }^{3}$ Respiratory Cell Research \& Pneumology, Lab 305, University Hospital Basel, Hebelstrasse 20, CH-4031 Basel, Switzerland
}

Correspondence should be addressed to Michael Roth, rothmic@uhbs.ch

Received 23 February 2009; Accepted 6 April 2009

Recommended by Paul Higgins

Therapy with hyperthermal chemotherapy in pleural diffuse malignant mesothelioma had limited benefits for patients. Here we investigated the effect of heat stress on heat shock proteins (HSP), which rescue tumour cells from apoptosis. In human mesothelioma and mesothelial cells heat stress $\left(39-42^{\circ} \mathrm{C}\right)$ induced the phosphorylation of two mitogen activated kinases (MAPK) Erk1/2 and p38, and increased Hsp40, and Hsp70 expression. Mesothelioma cells expressed more Hsp40 and were less sensitive to heat stress compared to mesothelial cells. Inhibition of Erk1/2 MAPK by PD98059 or by Erk1 siRNA down-regulated heat stress-induced Hsp40 and Hsp70 expression and reduced mesothelioma cell survival. Inhibition of p38MAPK by SB203580 or siRNA reduced Hsp40, but not Hsp70, expression and also increased mesothelioma cell death. Thus hyperthermia combined with suppression of $\mathrm{p} 38$ MAPK or Hsp40 may represent a novel approach to improve mesothelioma therapy.

Copyright (c) 2009 Michael Roth et al. This is an open access article distributed under the Creative Commons Attribution License, which permits unrestricted use, distribution, and reproduction in any medium, provided the original work is properly cited.

\section{Introduction}

Pleural Diffuse Malignant Mesothelioma (PDMM) is mainly induced by inhalation of asbestos crystals, or to a lesser extent by SV40 infection [1]. It was predicted that the cases of mesothelioma will decline after 2010, but recent studies indicated the persistence of new PDMM patients at a high level for another 10-15 years in Europe and in the USA; in other countries the rate may even further increase [1]. Unfortunately most PDMM cases are diagnosed at advanced stages and then PDMM are highly resistant to chemotherapeutic agents [1]. Locally applied heated (hyperthermal) chemotherapy had been suggested to improve the drug's effect on PDMM, but the expectations had been disappointing in most studies reporting only short term benefits for the patients [2-5]. Moreover, the effect of heat stress by itself had not been studied in detail in PDMM.

Normal mesothelial cells enable the pleural sheets of the rib cage and the lung to move freely. This function is hindered by asbestos fibres which induce a local inflammation of the pleura which is linked to the activation of intra cellular signalling proteins such as mitogen activated protein kinases (MAPK) and subsequent transcription factors. Asbestos especially, amphiboles and crionite induce, the malignant transformation of mesothelial cells by a mechanism that leads to a constitutive activation of intracellular signal transduction regulators including different MAPK and adhesion molecules $[6,7]$. Reactive oxygen radicals, induced by asbestos not only activates signal transduction, but also damages DNA [8] and together with continuous, incomplete wound repair in mesothelial cells may result in malignant transformation $[9,10]$. The observation that mesothelial cell proliferation is controlled by intracellular signalling proteins, mainly the MAPK Erk1/2 and p38 is of interest as both are activated by asbestos and by oxidative stress [11-15]. Furthermore, asbestos constitutively activates p38 MAPK in PDMM cells [14-16], however, the underlying mechanism and its contribution to PDMM cell proliferation is unclear.

Stress, including heat (hyperthermia), also induces intracellular signalling via Erk1/2 and p38 MAPK which may 
lead to either cell death or survival [17-19]. These two signalling pathways can stimulate the expression of heatshock-proteins (Hsp), Hsp27, Hsp40, and Hsp70 which can rescue tumour cells from cell death [19-23]. Hsp70 increases the resistance of PDMM cells to chemotherapeutic drugs [24]. Intracellular Hsp has been implicated in the protection of tumour cells from apoptosis of other tumour types it is implicated that intracellular Hsp protects tumour cells from apoptosis, while secreted Hsp stimulate the immune system to attack tumour cells [25-29]. Thus the question is if Hsp activation has a beneficial or worsening effect in PDMM therapy. Therefore, we investigated the effect of heat stress on MAPK, and Hsp expression in PDMM cells as well as the effect of both factors on the cell's survival.

\section{Material and Methods}

Cell Culture. Three human PDMM cell lines (NO36, STY51, ONE58,) were cultured and passaged as previously described [16]. One SV40 immortalised mesothelial cell line Met5 was used as control and cultivated as described earlier [15].

Heat Stress. Cells were seeded $\left(1 \times 10^{4} \mathrm{cells} / \mathrm{cm}^{2}\right)$ in RPMI 1640 (Invitrogen, Mount Waverley, Vic., Australia) supplemented with $5 \%$ fetal bovine serum (FBS) (JRH Biosciences, Inc., Lenexa, Kansas) in 12-well plates (Falcon Becton Dickinson, North Ryde, NSW, Australia) for 48-72 hours. The medium was then replaced with starving medium (RPMI 1640, 0.2\% FBS) for 24 hours, and then the cells were exposed to heat by placing the cell culture plates in a water bath for $0,5,10,20$ or 30 minutes at increasing temperature $\left(37,38,39,40,41,42^{\circ} \mathrm{C}\right)$. After heat stress, cells were placed into a $37^{\circ} \mathrm{C}, 5 \% \mathrm{CO}_{2}$ incubator at $100 \%$ humidity for $0,0.5$, 1,3 and 24 hours or 3 days.

Proliferation. Proliferation was determined by manual cell counts on the 3rd day after heat treatment using a Neubauer slide by standard procedures.

MAPK Function. For MAP kinase experiments, cells were pretreated for 1 hour with Erk1/2 MAP kinase inhibitor PD98059 $(10 \mu \mathrm{M})$, or p38 MAP kinase inhibitor SB203580 $(10 \mu \mathrm{M})$ (Calbiochem-Novabiochem Corp., Kilsyth, Vic., Australia). Alternatively, Erk1, and p38MAPK were down regulated for 24 hours by incubation with respective small inhibitory RNAs (siRNA) [catalogue number (cat number) SI00042462, cat number SI00025263, Qiagen, Hombrechtikon, Switzerland] or with siRNA for Hsp40 and Hsp70 (Qiagen), the final concentration of siRNA was $5 \mathrm{nM}$.

Cell Survival. Cell Survival was assessed by trypan-blue exclusion staining and by the expression of caspase-3 using a commercially available ELISA kit (R\&D System, Inc, Minneapolis, MN, cat number KM300).

Protein Extraction. Total protein was dissolved in Laemmli buffer as described earlier $(16,30)$. Nuclear and cytosalic proteins were isolated by a NE-PER reagent kit (cat number
23235, Pierce, Thermo Scientific, Lausanne, Switzerland) as described by the distributor.

Immuno-Blotting. Total all protein $(10 \mu \mathrm{g})$ was denatured $\left(95^{\circ} \mathrm{C}, 5\right.$ minutes), chilled on ice (5 minutes), centrifuged $(13,000 \times \mathrm{g}, 50$ seconds), and applied to electrophoresis (4\%-15\% SDS-PAGE). Proteins were transferred onto two sandwiched PVDF membranes by over night transfer at $50^{\circ} \mathrm{C}$ (buffer), which was confirmed by staining of one membrane with Coomasie Blue, the 2nd membrane was washed three times with PBS, blocked with 5\% skimmed milk in PBS $\left(4^{\circ} \mathrm{C}\right.$, overnight), and incubated with one of the primary antibodies (CellSignal Technol. Inc, Danvers, MA: Cat number 9212: p38 MAPK; phos-p38: number 9215; Erk1/2: number 9122; phos-Erk1/2 : number 4377; Hsp40: number 4868, Hsp70: number 4876) for 1 hour at room temperature. Unbound antibodies were washed and membranes were incubated with horseradish-labelled species-specific secondary antibodies for 1 hour (room temperature). After washing $(3 \times 15$ minutes $)$ the membranes with blocking buffer bound antibody signals were detected by ECL substrate and documented on X-ray film [30].

Statistical Analysis. All data were analyzed by ANOVA and Fischer PLSD test, unless stated otherwise.

\section{Results}

Compared to the cell numbers at the day of seeding $(10,000$ cells $/ \mathrm{cm}^{2}$ ) cell counts increased by $60 \%$ over 3 days in both mesothelial and PDMM cells and heat stress $\left(41^{\circ} \mathrm{C}, 10\right.$ minutes) significantly reduced proliferation in PDMM cells after 3 days (student's $t$-test, paired, two-tailed: $P<.01$ ) (Figure 1(a)). Interestingly non-malignant mesothelial cells were significantly more sensitive to increasing temperature compared to PDMM cells. In mesothelial cells kept at $37^{\circ} \mathrm{C}$, a temperature increase to $>39^{\circ} \mathrm{C}$ for 20 minutes significantly reduced cell proliferation $(P<.01$, Figure $1(\mathrm{~b}))$. In both cell types the inhibition of proliferation correlated inversely with temperature increase and duration of heat stress (Figure 1(b)).

As we reported earlier p38 MAPK was constitutively activated in PDMM cells [15] and heat stress did not modify this effect (Figure 2(a)). In contrast in mesothelial cells temperatures higher than $40^{\circ} \mathrm{C}$ activated the phosphorylation of p38MAPK within 10 minutes, while the content of total p38 MAPK was not altered (Figure 2(b)).

A low level of active Erk1/2 MAPK was detected in the nuclear protein fraction of cells grown at $37^{\circ} \mathrm{C}$, and heat stress increased the level of total Erk1/2 MAPK and significantly stimulated the phosphorylation of Erk1/2 MAPK in the nuclear protein fraction (Figure 2(c)). When treated with temperatures $>40^{\circ} \mathrm{C}$ the accumulation of phosphorylated Erk1/2 MAPK increased within 10 minutes and decline after 30 minutes (Figure 2(c)). We observed no differences for Erk1/2 MAPK phosphorylation comparing PDMM to mesothelial cells (data not shown). 


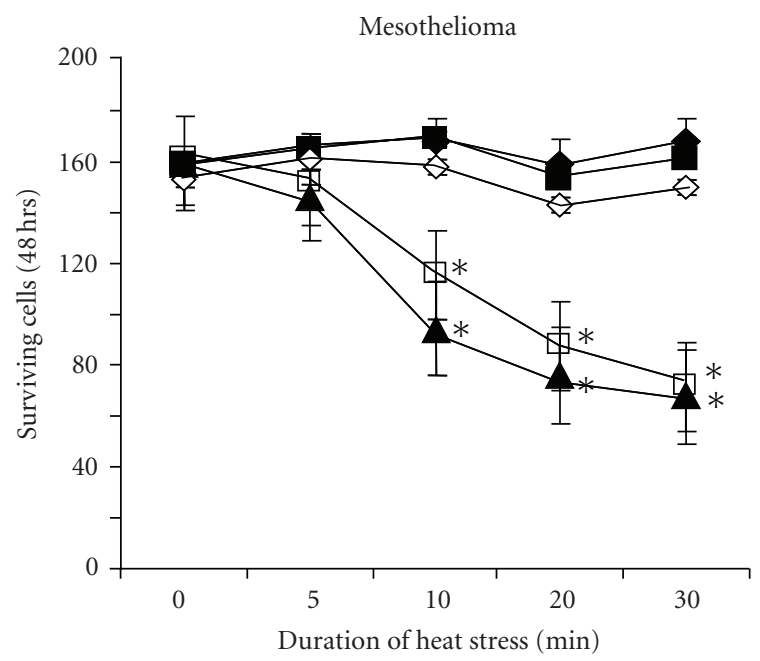

Temperature

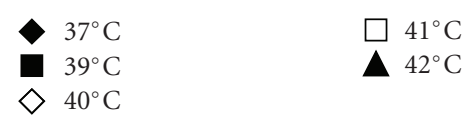

(a)

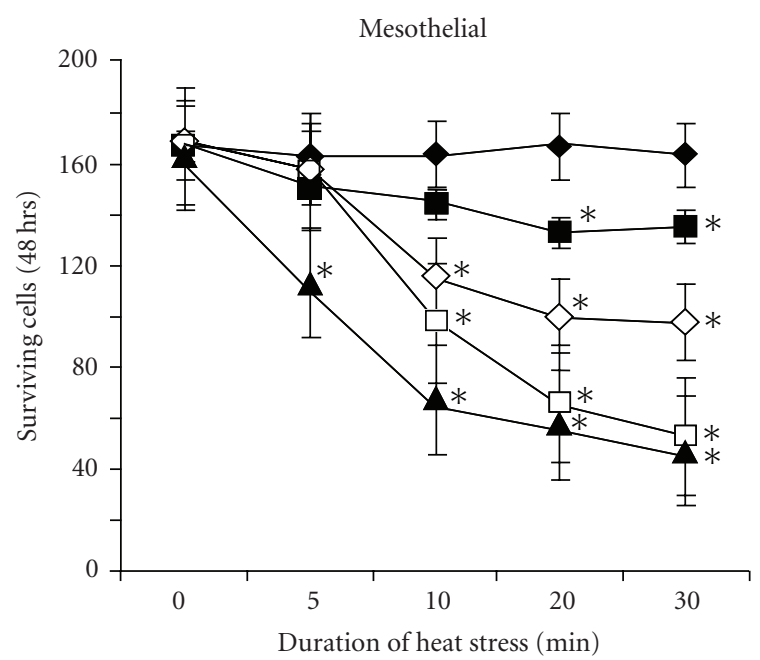

Temperature

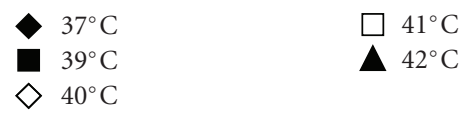

(b)

Figure 1: Heat stress induced cell death in (a) mesothelioma cell lines $(n=3)$ and (b) one mesothelial cell line. Viability was determined by manual cell counting of trypan blue exclusion stained cells 3 days after heat stress. $*$ indicates $P<.01$ compared to cells at $37^{\circ} \mathrm{C}$. Each data point represents the mean \pm S.E.M.of three independent experiments in each cell line.

At $37^{\circ} \mathrm{C}$ Hsp 40 and Hsp 70 were expressed at low levels by mesothelial cells (Figure 3(a)) and PDMM cells (Figure 3(b)). In mesothelial cells heat stress above $40^{\circ} \mathrm{C}$ increased the expression of Hsp70 within 24 hours (Figure 3(a)), while Hsp40 was already expressed at $37^{\circ} \mathrm{C}$ and declined 6 hours after heat stress $\left(40^{\circ} \mathrm{C}, 20\right.$ minutes $)$, and increased to the initial level after 48 hours (Figure 3(a)). In PDMM cells heat stress $\left(40^{\circ} \mathrm{C}, 20\right.$ minutes $)$ stimulated Hsp70 expression at 6 hours with a further increase until 48 hours (Figure 3(b)). In contrast to mesothelial cells in PDMM cells also Hsp40 was strongly upregulated by heat stress $\left(40^{\circ} \mathrm{C}, 20\right.$ minutes) at 24 and 48 hours (Figure 3(b)).

When PDMM cells were pre-treated for 1 hour with either a chemical inhibitor for Erk1/2 (PD98059, $10 \mu \mathrm{M}$ ) or for 24 hours with Erk1 MAPK siRNA, we observed an incomplete reduction of Hsp70 and a total decrease of Hsp40 (Figure 3(c)). The suppression of p38 MAPK by either a chemical inhibitor (SB203580, $10 \mu \mathrm{M})$ or by $\mathrm{p} 38$ MAPK siRNA downregulated the heat-induced $\left(40^{\circ} \mathrm{C}, 20\right.$ minutes) expression of Hsp70 and reduced that of Hsp40 to a lesser degree in PDMM cells (Figure 3(d)). The downregulation of p38 and Erk1/2 MAPK had similar effects on heat-induced Hsp40 and Hsp70 expression in mesothelial cells (data not shown). In Figure 3(e) we provide proof that pretreatment with either the chemical inhibitors or with the respective siRNAs (24 hours) specifically down-regulated the expression and phosphorylation of Erk1 and p38 MAPK in PDMM cells.

The suppression of Erk1/2 MAPK significantly reduced proliferation of mesothelial and PDMM cells under normal conditions $\left(10 \%\right.$ FCS, $\left.37^{\circ} \mathrm{C}\right)$ (Figure $\left.4(\mathrm{a})\right)$. When pretreated (1 hour) with p38 MAPK siRNA (10 nM) only the proliferation of PDMM cells was significantly reduced at $37^{\circ} \mathrm{C}$, while that of mesothelial cells was not affected (Figure 4(b)). Pre-treatment with either p38 or Erk1 MAPK siRNA increased the heat sensitivity of PDMM cells, which was reflected in significantly reduced cell counts after 3 days (Figure 4(b)). Interestingly, the survival of heat stress in mesothelial cells was not further reduced by p38 MAPK inhibition (Figure 4(a)), but was completely abrogated by inhibition of Erk1/2 MAPK (Figure 4(b)).

In PDMM cells, down-regulation of $\mathrm{Hsp} 40$ by specific siRNA did not affect the basic proliferation rate, but significantly increased the cell's sensitivity to heat stress, with a maximal reduced proliferation after a 20 minutes exposure to temperatures $>40^{\circ} \mathrm{C}$ (Figure 5(a)). Similarly, the down-regulation of Hsp70 by siRNA did not alter the basic proliferation of PDMM cells, but also increased the cell's sensitivity to heat stress, however, with a much lower effect compared to Hsp40 inhibition (Figure 5(b)). For mesothelial cells the inhibition of Hsp40 also increased their sensitivity to heat (Figure 5(a)), but inhibition of Hsp70 had no effect at all (Figure 5(b)).

We also assessed the synthesis of caspase- 3 as an indicator for apoptosis in heat stressed cells but observed only a relative small increase of caspase- 3 levels by PDMM cells which did not correlate with the increase of the temperature (Figure 5(c)).

\section{Discussion}

This study provides evidence that mesothelial cells produce less Hsp40 than PDMM cells and are therefore, more sensitive to heat stress than PDMM cells. PDMM cells escape 


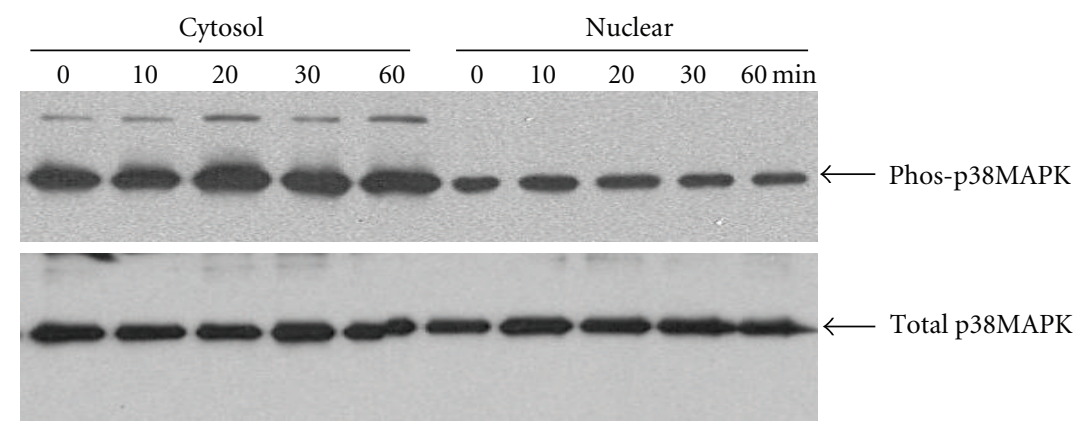

(a)
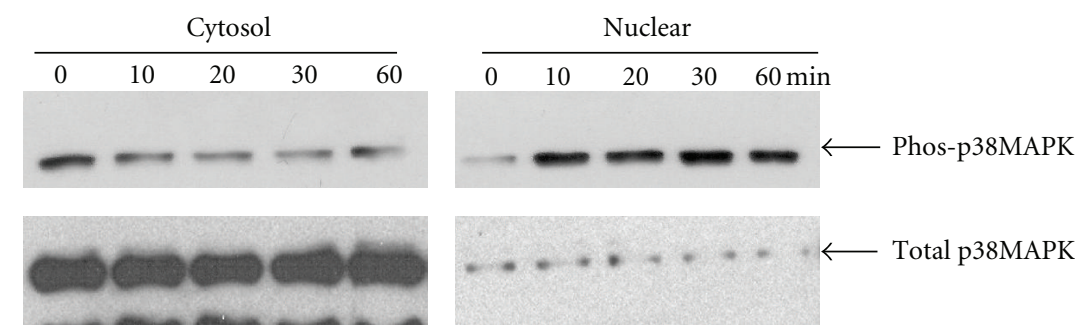

(b)
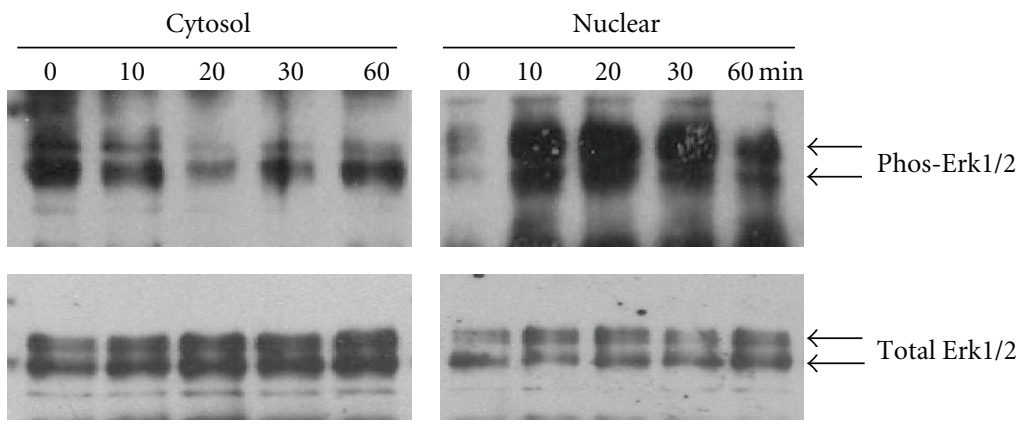

(c)

FIGURE 2: Heat stress activates phosphorylation of Erk1/2 and p38 MAPK. (a) Representative immunoblot of p38 MAPK phosphorylation and nuclear accumulation by heat stress $\left(40^{\circ} \mathrm{C}, 20\right.$ minutes) in mesothelial cells. Similar results were obtained in two additional experiments. Coomasie blue was used to control equal protein loading (loading control). (b) representative immunoblot of constitutive p38 MAPK phosphorylation in PDMM cells (LO68). Similar results were obtained in the other two PDMM cell lines. (c) representative immunoblot of Erk1/2 phosphorylation and nuclear accumulation after heat stress $\left(40^{\circ} \mathrm{C}, 20\right.$ minutes) in PDMM cells (LO68). Similar results were obtained with two other PDMM cell lines and in mesothelial cells.

hyperthermia by expressing both Hsp40 and Hsp70 via the activation of Erk1/2 and p38 MAPK. The constitutively active p38 MAPK by PDMM cells was essential for the expression of Hsp40 and Hsp70, while Erk1/2 MAPK seemed to play less important role. Importantly, the down-regulation of either Hsp40 or Hsp70 or p38MAPK increased the heat sensitivity of PDMM cells.

Several studies indicated that the malignant transformation of mesothelial cells is linked to a modification of p38 MAPK activity and its interaction with Erk1/2 MAPK on a yet to be defined level, which is essential for the malignant transformation [12-15]. The interaction of Erk1/2 with p38MAPK is necessary to prevent cells from entering apoptosis [26]. This report is in line with our observation of constitutively activated p38 MAPK [16] and low expression of caspase-3 in PDMM cells also after heat exposure. It had been suggested by another study that caspase- 3 expression by PDMM cells correlated with resistance to apoptotic stimuli [31].

Increase expression of Hsp70 correlated with low levels of the cell cycle inhibiting protein $\mathrm{p} 21^{\text {(Waf1/Cipl) }}$ which would mediated apoptosis in ovarian and PDMM cells [24]. However, in most cell types, including tumour cells, the antiapoptotic effect of Hsp70 depends on its interaction with Hsp40 [26, 32-35].

The function of Hsp is that of chaperons which rescue and re-constitute the folding of proteins if they have been misfolded by various stress factors, such as oxygen radicals or heat [33-36]. Hsp40 especially inhibited the action of proteasomes which, when activated, degrade a wide variety 


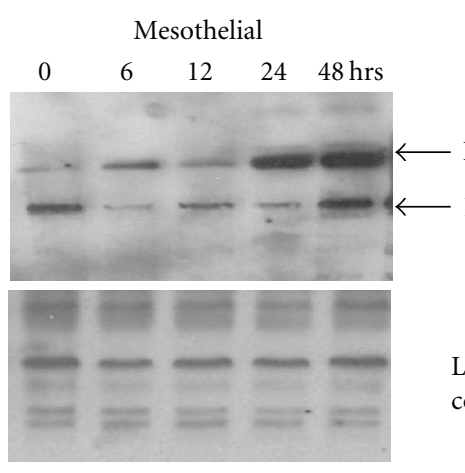

(a)

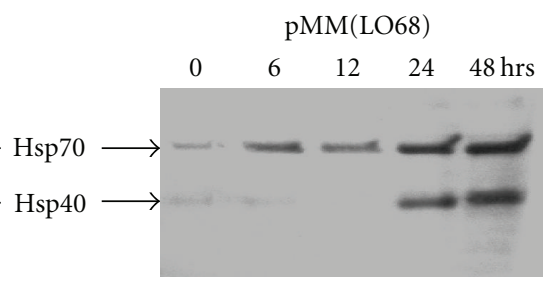

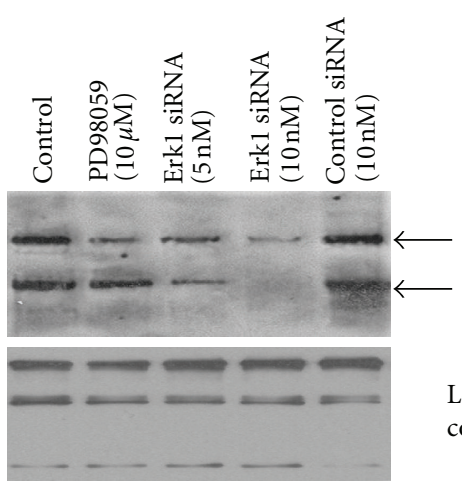

(c)

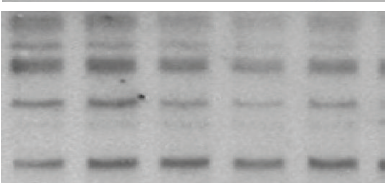

(b)
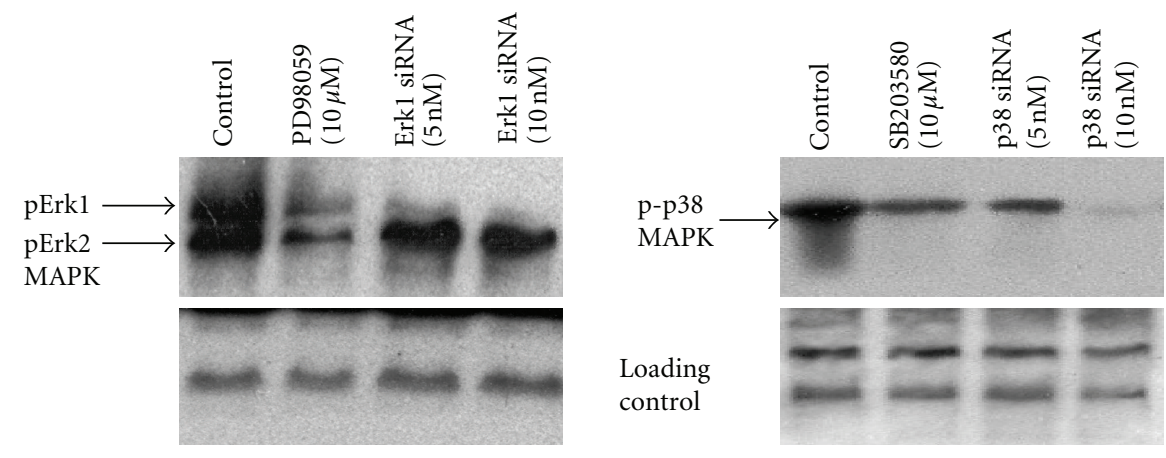

(e)

FIgURE 3: Heat stress induces Hsp expression. Representative immunoblots of of Hsp70 and Hsp40 expression after heat stress $\left(40^{\circ} \mathrm{C}, 20\right.$ minutes) by (a) mesothelial cells and (b) PDMM cells (LO68). (c) Erk1/2 MAPK mediated the heat stress-induced (40 ${ }^{\circ}$, 20 minutes) expression of Hsp70 and Hsp40 by PDMM cells (LO68). (d) p38 MAPK mediated heat stress-induced $\left(40^{\circ} \mathrm{C}, 20\right.$ minutes) expression of Hsp40 and Hsp70 expressions in PDMM cells (LO68). Similar results were obtained in the two other PDMM cell lines and in mesothelial cells. (e) Specific protein suppression by siRNAs for Erk1 or p38 MAPK in PDMM cells (LO68). Coomasie blue was used to control equal protein loading (loading control).

of proteins leading to cell death [34]. Thus Hsp are an important highly conserved protein family that is essential for the survival of all cell types under stress conditions [32]. In line with other studies our data indicated that Hsp70 alone is a weak inhibitor of heat induced cell death, while the inhibition of Hsp40 significantly increased PDMM cell's sensitivity to heat stress.

In our study, heat stress increased Hsp70 expression via the preceding activation of the signal transducer Erk1/2
MAPK. These results are in line with studies in different tumour types and indicate an oxygen sensing mechanism for Erk1/2 and p38 MAPK [18-23]. However, the induction of Hsp40 by heat via the activation of Erk1/2 MAPK had only been indicated indirectly in T-cells $[37,38]$. In regard to PDMM asbestos fibres cause oxygen radical formation $[14,15]$ and which Erk1/2 MAPK activity $[11,12]$ may prime PDMM cells to survive heat stress or increase their resistance to chemotherapy. Taking into account that down-regulation 


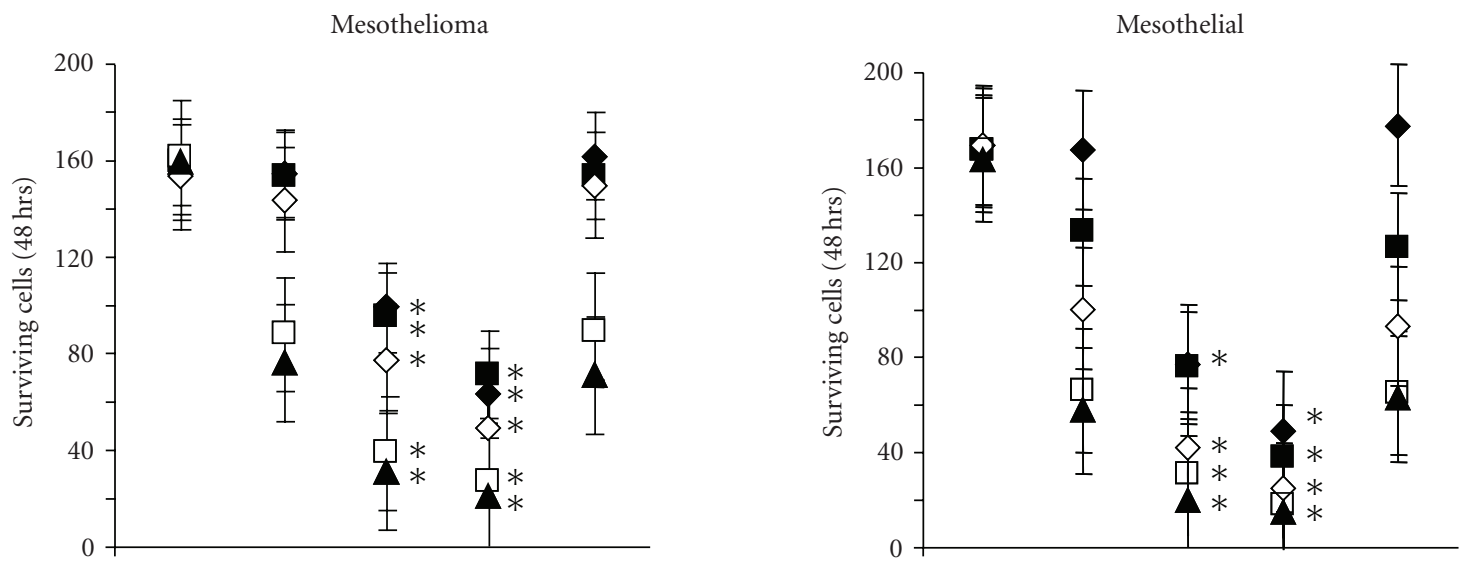

\begin{tabular}{|c|c|c|c|c|c|c|c|c|}
\hline Control & & & & & + & & & \\
\hline Heat & + & + & + & + & + & + & + & + \\
\hline Erk1 siRNA (5 nM) & & + & & & & + & & \\
\hline Erk1 siRNA (10 nM) & & & + & & & & + & \\
\hline Control siRNA $(10 \mathrm{nM})$ & & & & + & & & & + \\
\hline
\end{tabular}

(a)
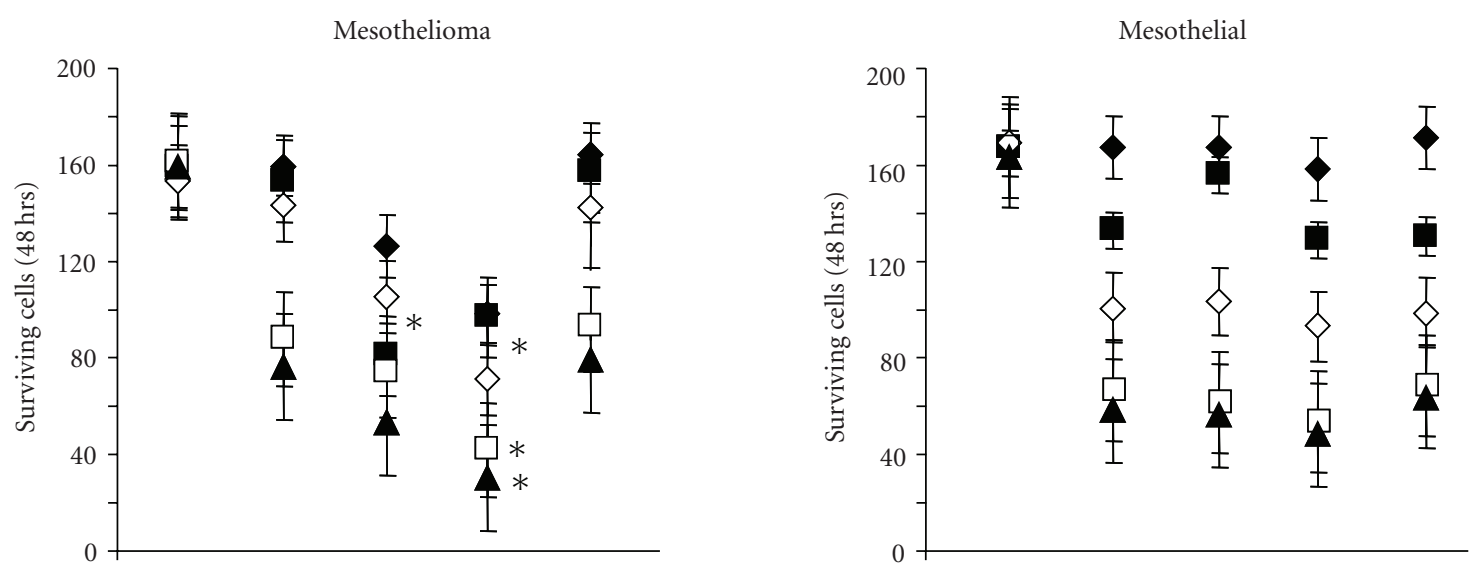

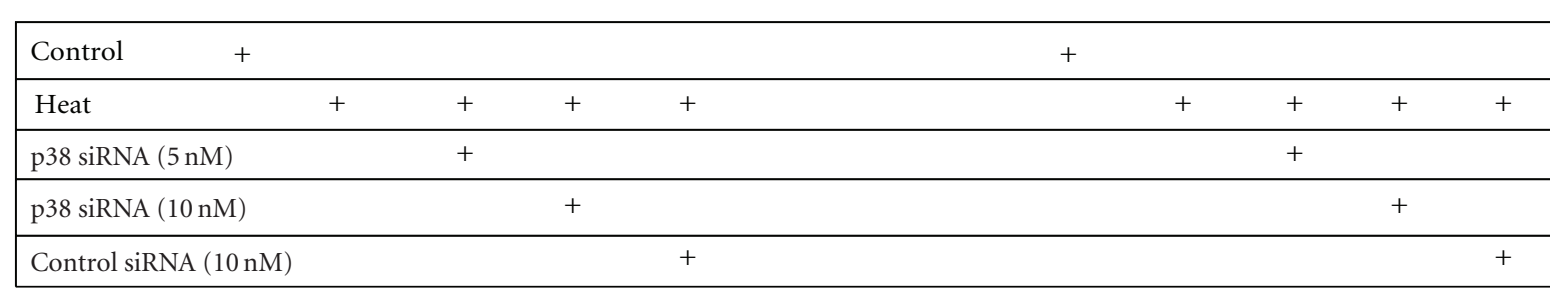

$\begin{array}{ll}\text { Temperature } & \\ 37^{\circ} \mathrm{C} & \square 41^{\circ} \mathrm{C} \\ 39^{\circ} \mathrm{C} & \boldsymbol{\Delta} 42^{\circ} \mathrm{C} \\ \diamond 40^{\circ} \mathrm{C} & \end{array}$

(b)

FIgure 4: The role of Erk1/2 and p38 MAPK in heat stress-induced cell death in PDMM and mesothelial cells. (a) Cell were pre-incubated with 5 or $10 \mathrm{nM}$ of Erk1 MAPK small inhibitory (si)RNA and then exposed to various temperatures $\left(39-42^{\circ} \mathrm{C}\right)$ for 20 minutes. Following cells were kept under normal growth conditions for 48 hours and viable cells were counted by trypan blue exclusion staining. (b) Cells were preincubated with 5 or $10 \mathrm{nM}$ of p38 MAPK siRNA as described above (a) and viable cells were counted after trypan blue exclusion staining. Data points represent the mean \pm S.E.M. of triplicate experiments. $*$ indicates $P<.01$ (student's paired $t$-test, two-tailed). 

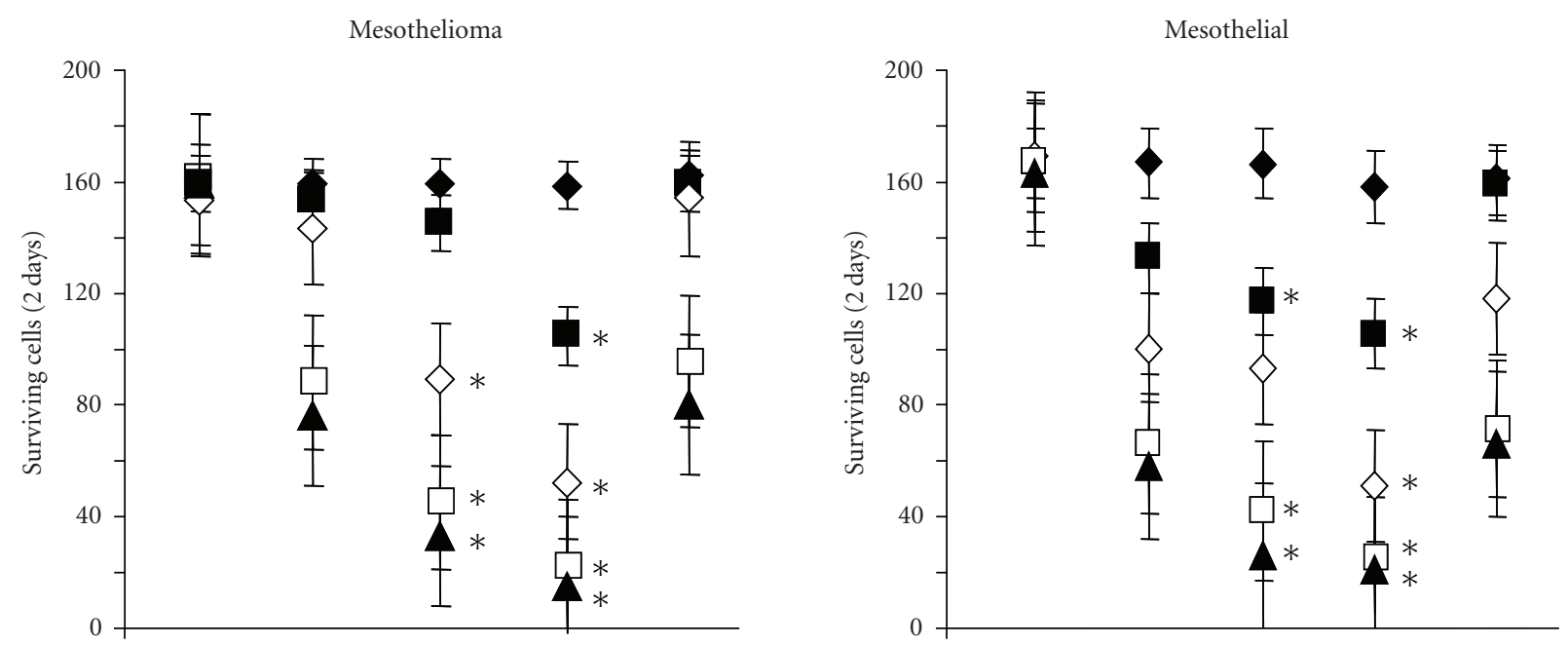

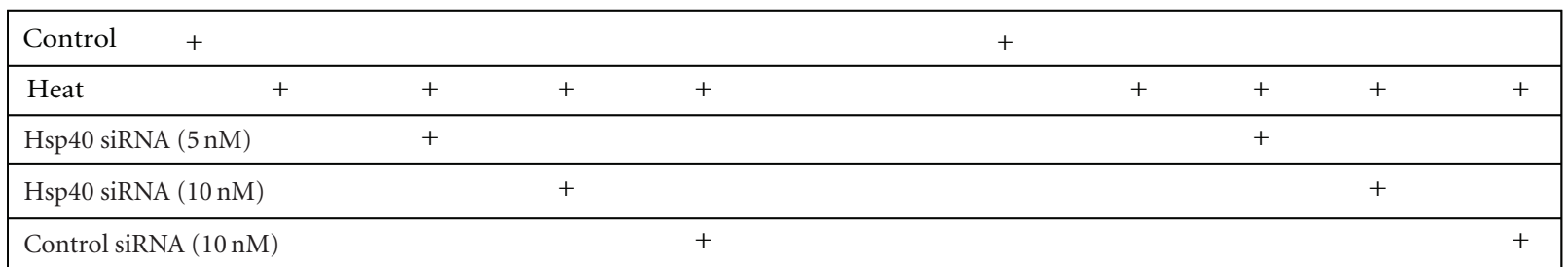

(a)
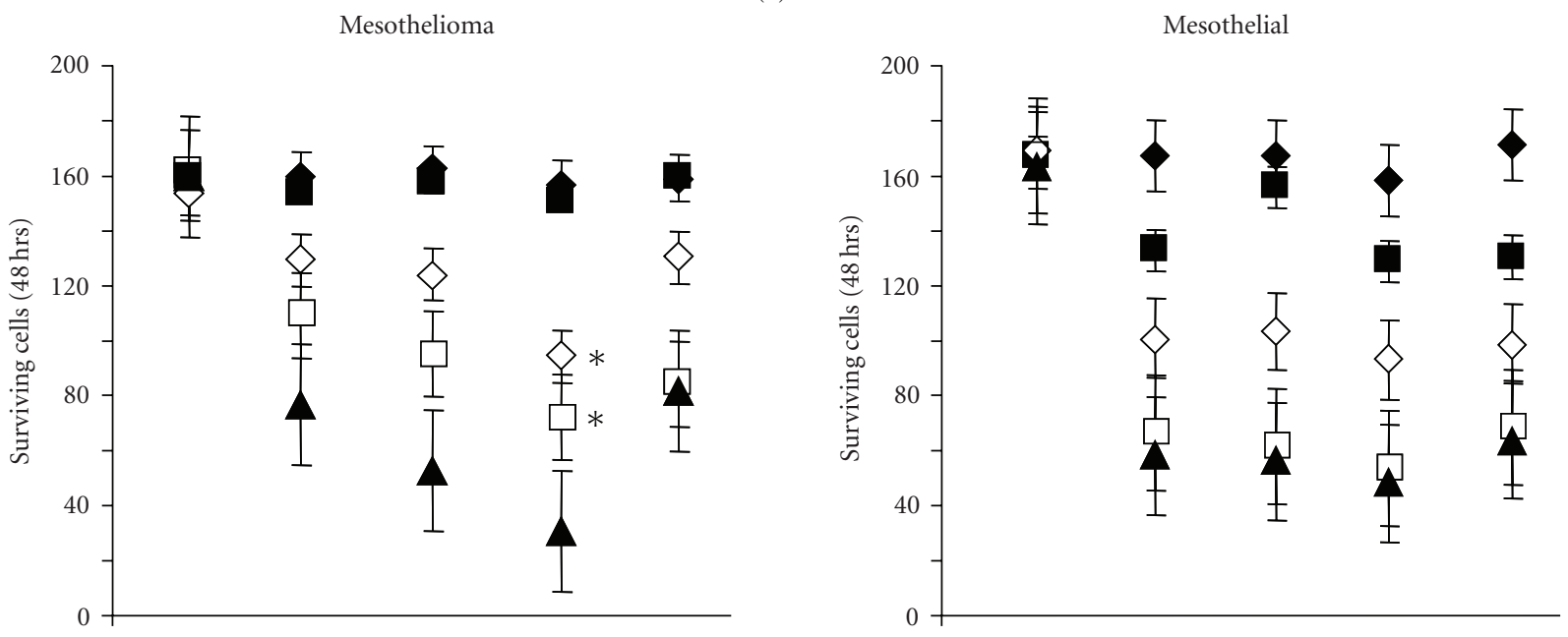

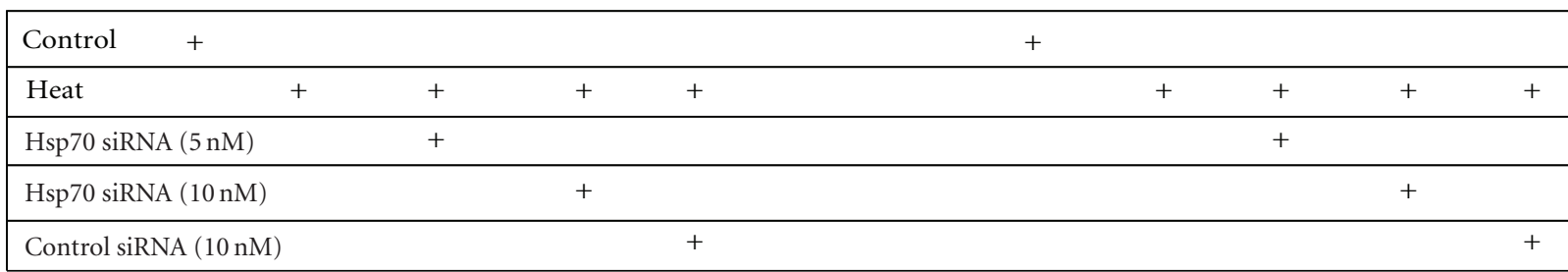

Temperature

- $37^{\circ} \mathrm{C}$

$\square 41^{\circ} \mathrm{C}$

$39^{\circ} \mathrm{C}$

$\triangle 42^{\circ} \mathrm{C}$

(b)

FIgURe 5: Continued. 


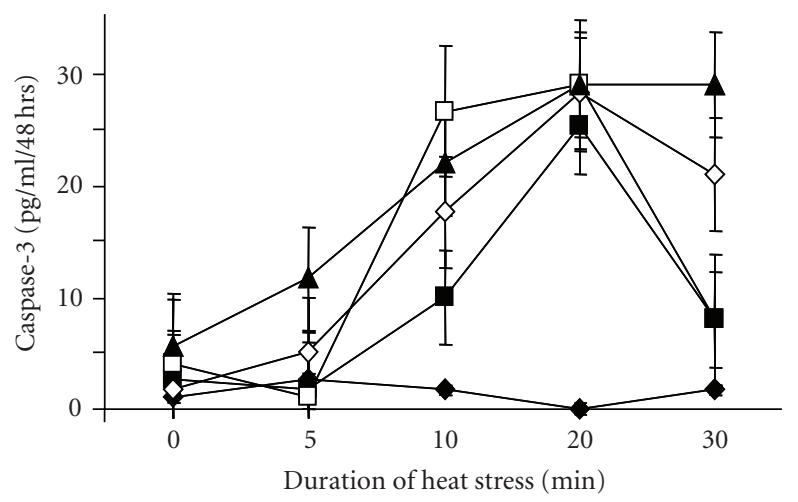

Temperature

$\begin{array}{ll}\diamond 37^{\circ} \mathrm{C} & \square 41^{\circ} \mathrm{C} \\ \diamond 39^{\circ} \mathrm{C} & \Delta 42^{\circ} \mathrm{C} \\ \diamond 40^{\circ} \mathrm{C} & \end{array}$

(c)

Figure 5: Hsp40/70 rescue cells from heat stress. (a) Cells were pre-incubated with 5 or $10 \mathrm{nM}$ of Hsp40 siRNA and then exposed to increasing heat stress $\left(39-42^{\circ} \mathrm{C}\right)$ for 20 minutes. Following cells were kept under normal growth conditions for 48 hours and viable cells were counted after trypan blue exclusion staining. (b) Cells were pre-incubated with 5 or $10 \mathrm{nM}$ of Hsp70 siRNA and treated as described above "a". Data points represent the mean \pm S.E.M. of triplicate experiments. $*$ indicates $P<.01$ compared to control (student's paired $t$ test, two-tailed). (c) Expression of caspase-3 by PDMM treated for various time intervals with increasing temperatures. Data points represent the mean \pm S.E.M. of triplicate experiments.

of either Erk1/2 or Hsp40 most effectively disrupted the rescue of PDMM cells from heat stress-induced cell death implicates its important role in the rescue and survival. However, as Erk1/2 MAPK was also the most important mediator of growth for mesothelial cells and its suppression killed most cells. Therefore, we suggest that the inhibition of Hsp40 would be the best option to increase heat sensitivity of PDMM cells.

The induction of Hsp70 via p38 MAPK had been described in other cell types, including human asterocytes, cardiac cells, fibroblasts, head and neck cancer cells [1824]. However in PDMM cells, p38 MAPK was constitutively activated [13-16] and needed the interaction with Erk1/2 MAPK to increase Hsp expression. This constitutively active p38 MAPK together with Erk1/2 MAPK are central for PDMM cell proliferation. Compared to other studies, our data implies that p38 MAPK is controlling Hsp70 expression in PDMM by a different mechanism more than in nontransformed cells [18-23,39]. This might indicate a cell type specific effect or a special modification of signalling linked to the transformation of mesothelial cells. In contrast to other tumour types a central role of Hsp70 in heat stress survival is indicated for PDMM $[32,39]$. Thus, we conclude that it might be more effective to suppress both Hsp40 and Hsp70 to sensitize PDMM cells to heat; however, under the condition of this study we did not observe any synergistic effect.

In summary, our data suggest that PDMM cells respond to heat stress with an increased production of the stress proteins Hsp40 and Hsp70 that rescue them from death. Therefore the inhibition of Hsp40/Hsp70 or Erk1/2 MAPK might present a new option to increase the success of hyperthermia in mesothelioma.

\section{Aknowlegdements}

The authors would like to thank Mr. C. T. S'ng for his help to prepare this manuscript. This work was funded by unrestricted research grants from the "Werner und Hedy BergerJanser Stiftung zur Erforschung der Krebskrankheiten," Bern, Switzerland, and by Grant of the "Krebs beider Basel" (no. 02-2008).

\section{References}

[1] B. W. S. Robinson and R. A. Lake, "Advances in malignant mesothelioma," The New England Journal of Medicine, vol. 353, no. 15, pp. 1591-1603, 2005.

[2] E. de Bree, S. van Ruth, P. Baas, et al., "Cytoreductive surgery and intraoperative hyperthermic intrathoracic chemotherapy in patients with malignant pleural mesothelioma or pleural metastases of thymoma," Chest, vol. 121, no. 2, pp. 480-487, 2002.

[3] W. G. Richards, L. Zellos, R. Bueno, et al., "Phase I to II study of pleurectomy/decortication and intraoperative intracavitary hyperthermic cisplatin lavage for mesothelioma," Journal of Clinical Oncology, vol. 24, no. 10, pp. 1561-1567, 2006.

[4] P. H. Sugarbaker, "Laboratory and clinical basis for hyperthermia as a component of intracavitary chemotherapy," International Journal of Hyperthermia, vol. 23, no. 5, pp. 431442, 2007. 
[5] V. L. Roggli, A. Sharma, K. J. Butnor, T. Sporn, and R. T. Vollmer, "Malignant mesothelioma and occupational exposure to asbestos: a clinicopathological correlation of 1445 cases," Ultrastructural Pathology, vol. 26, no. 2, pp. 55-65, 2002.

[6] P. Bertino, A. Marconi, L. Palumbo, et al., "Erionite and asbestos differently cause transformation of human mesothelial cells," International Journal of Cancer, vol. 121, no. 1, pp. 12-20, 2007.

[7] K. Pelin, A. Hirvonen, and K. Linnainmaa, "Expression of cell adhesion molecules and connexins in gap junctional intercellular communication deficient human mesothelioma tumour cell lines and communication competent primary mesothelial cells," Carcinogenesis, vol. 15, no. 11, pp. 26732675, 1994.

[8] D. W. Kamp, V. A. Israbian, S. E. Preusen, C. X. Zhang, and S. A. Weitzman, "Asbestos causes DNA strand breaks in cultured pulmonary epithelial cells: role of iron-catalyzed free radicals," American Journal of Physiology, vol. 268, no. 3, pp. L471-L480, 1995.

[9] J. T. Hodgson and A. Darnton, "The quantitative risks of mesothelioma and lung cancer in relation to asbestos exposure," Annals of Occupational Hygiene, vol. 44, no. 8, pp. 565-601, 2000.

[10] K.-Y. Hung, C.-T. Chen, C.-J. Yen, P.-H. Lee, T.-J. Tsai, and B.-S. Hsieh, "Dipyridamole inhibits PDGF-stimulated human peritoneal mesothelial cell proliferation," Kidney International, vol. 60 , no. 3, pp. 872-881, 2001.

[11] C. A. Barlow, T. F. Barrett, A. Shukla, B. T. Mossman, and K. M. Lounsbury, "Asbestos-mediated CREB phosphorylation is regulated by protein kinase A and extracellular signalregulated kinases 1/2," American Journal of Physiology, vol. 292, no. 6, pp. L1361-L1369, 2007.

[12] C. L. Zanella, J. Posada, T. R. Tritton, and B. T. Mossman, "Asbestos causes stimulation of the extracellular signalregulated kinase 1 mitogen-activated protein kinase cascade after phosphorylation of the epidermal growth factor receptor," Cancer Research, vol. 56, no. 23, pp. 5334-5338, 1996.

[13] L. Vintman, S. Nielsen, A. Berner, R. Reich, and B. Davidson, "Mitogen-activated protein kinase expression and activation does not differentiate benign from malignant mesothelial cells," Cancer, vol. 103, no. 11, pp. 2427-2433, 2005.

[14] W. A. Swain, K. J. O'Byrne, and S. P. Faux, "Activation of p38 MAP kinase by asbestos in rat mesothelial cells is mediated by oxidative stress," American Journal of Physiology, vol. 286, no. 4, pp. L859-L865, 2004.

[15] S. Wakchoure, M. A. Merrell, W. Aldrich, et al., "Bisphosphonates inhibit the growth of mesothelioma cells in vitro and in vivo," Clinical Cancer Research, vol. 12, no. 9, pp. 2862-2868, 2006.

[16] J. Zhong, M. M. Gencay, L. Bubendorf, et al., "ERK1/2 and p38 MAP kinase control MMP-2, MT1-MMP, and TIMP action and affect cell migration: a comparison between mesothelioma and mesothelial cells," Journal of Cellular Physiology, vol. 207, no. 2, pp. 540-552, 2006.

[17] S. Inoue, H. Motoda, Y. Koike, K. Kawamura, F. Hiragami, and Y. Kano, "Microwave irradiation induces neurite outgrowth in PC12m3 cells via the p38 mitogen-activated protein kinase pathway," Neuroscience Letters, vol. 432, no. 1, pp. 35-39, 2008.

[18] E. R. Nielsen, Y. E. G. Eskildsen-Helmond, and S. I. S. Rattan, "MAP kinases and heat shock-induced hormesis in human fibroblasts during serial passaging in vitro," Annals of the New York Academy of Sciences, vol. 1067, pp. 343-348, 2006.
[19] C. D. Venkatakrishnan, A. K. Tewari, L. Moldovan, et al., "Heat shock protects cardiac cells from doxorubicin-induced toxicity by activating p38 MAPK and phosphorylation of small heat shock protein 27," American Journal of Physiology, vol. 291, no. 6, pp. H2680-H2691, 2006.

[20] N. Narita, I. Noda, T. Ohtsubo, et al., "Analysis of heat-shock related gene expression in head-and-neck cancer using cDNA arrays," International Journal of Radiation Oncology, Biology, Physics, vol. 53, no. 1, pp. 190-196, 2002.

[21] A. R. Taylor, M. B. Robinson, D. J. Gifondorwa, M. Tytell, and C. E. Milligan, "Regulation of heat shock protein 70 release in astrocytes: role of signaling kinases," Developmental Neurobiology, vol. 67, no. 13, pp. 1815-1829, 2007.

[22] P. Rafiee, M. E. Theriot, V. M. Nelson, et al., "Human esophageal microvascular endothelial cells respond to acidic pH stress by PI3K/AKT and p38 MAPK-regulated induction of Hsp70 and Hsp27," American Journal of Physiology, vol. 291, no. 5, pp. C931-C945, 2006.

[23] L. Schiaffonati, P. Maroni, P. Bendinelli, L. Tiberio, and R. Piccoletti, "Hyperthermia induces gene expression of heat shock protein 70 and phosphorylation of mitogen activated protein kinases in the rat cerebellum," Neuroscience Letters, vol. 312, no. 2, pp. 75-78, 2001.

[24] W. Hu, W. Wu, S.-C. Yeung, R. S. Freedman, J. J. Kavanagh, and C. F. Verschraegen, "Increased expression of heat shock protein 70 in adherent ovarian cancer and mesothelioma following treatment with manumycin, a farnesyl transferase inhibitor," Anticancer Research, vol. 22, no. 2A, pp. 665-672, 2002.

[25] S. K. Calderwood and D. R. Ciocca, "Heat shock proteins: stress proteins with Janus-like properties in cancer," International Journal of Hyperthermia, vol. 24, no. 1, pp. 31-39, 2008.

[26] A. Ito, H. Honda, and T. Kobayashi, "Cancer immunotherapy based on intracellular hyperthermia using magnetite nanoparticles: a novel concept of "heat-controlled necrosis" with heat shock protein expression," Cancer Immunology, Immunotherapy, vol. 55, no. 3, pp. 320-328, 2006.

[27] R. A. Coss, "Inhibiting induction of heat shock proteins as a strategy to enhance cancer therapy," International Journal of Hyperthermia, vol. 21, no. 8, pp. 695-701, 2005.

[28] V. Milani and E. Noessner, "Effects of thermal stress on tumor antigenicity and recognition by immune effector cells," Cancer Immunology, Immunotherapy, vol. 55, no. 3, pp. 312-319, 2006.

[29] H. P. Kim, X. Wang, J. Zhang, et al., "Heat shock protein70 mediates the cytoprotective effect of carbon monoxide: involvement of $\mathrm{p} 38 \beta$ MAPK and heat shock factor-1," The Journal of Immunology, vol. 175, no. 4, pp. 2622-2629, 2005.

[30] O. Eickelberg, M. Roth, R. Lörx, et al., "Ligand-independent activation of the glucocorticoid receptor by $\beta_{2}$-adrenergic receptor agonists in primary human lung fibroblasts and vascular smooth muscle cells," The Journal of Biological Chemistry, vol. 274, no. 2, pp. 1005-1010, 1999.

[31] Y. Soini, K. Kahlos, R. Sormunen, et al., "Activation and relocalization of caspase 3 during the apoptotic cascade of human mesothelioma cells," APMIS, vol. 113, no. 6, pp. 426435, 2005.

[32] C. Jolly and R. I. Morimoto, "Role of the heat shock response and molecular chaperones in oncogenesis and cell death," Journal of the National Cancer Institute, vol. 92, no. 19, pp. 1564-1572, 2000.

[33] C.-Y. Fan, S. Lee, and D. M. Cyr, "Mechanisms for regulation of Hsp70 function by Hsp40," Cell Stress and Chaperones, vol. 8, no. 4, pp. 309-316, 2003. 
[34] S.-A. Kim, S. Chang, J.-H. Yoon, and S.-G. Ahn, "TATHsp40 inhibits oxidative stress-mediated cytotoxicity via the inhibition of Hsp70 ubiquitination," FEBS Letters, vol. 582, no. 5, pp. 734-740, 2008.

[35] R. Kaneko, Y. Hayashi, I. Tohnai, M. Ueda, and K. Ohtsuka, "Hsp40, a possible indicator for thermotolerance of murine tumour in vivo," International Journal of Hyperthermia, vol. 13, no. 5, pp. 507-516, 1997.

[36] Y. Uchiyama, N. Takeda, M. Mori, and K. Terada, "Heat shock protein 40/DjB1 is required for thermotolerance in early phase," Journal of Biochemistry, vol. 140, no. 6, pp. 805-812, 2006.

[37] R. E. Marks, A. W. Ho, C. Robbel, T. Kuna, S. Berk, and T. F. Gajewski, "Farnesyltransferase inhibitors inhibit T-cell cytokine production at the posttranscriptional level," Blood, vol. 110, no. 6, pp. 1982-1988, 2007.

[38] R. Kurzrock, H. M. Kantarjian, J. E. Cortes, et al., "Farnesyltransferase inhibitor R115777 in myelodysplastic syndrome: clinical and biologic activities in the phase 1 setting," Blood, vol. 102, no. 13, pp. 4527-4534, 2003.

[39] M. Garmyn, T. Mammone, A. Pupe, D. Gan, L. Declercq, and D. Maes, "Human keratinocytes respond to osmotic stress by p38 map kinase regulated induction of HSP70 and HSP27," The Journal of Investigative Dermatology, vol. 117, no. 5, pp. 1290-1295, 2001. 

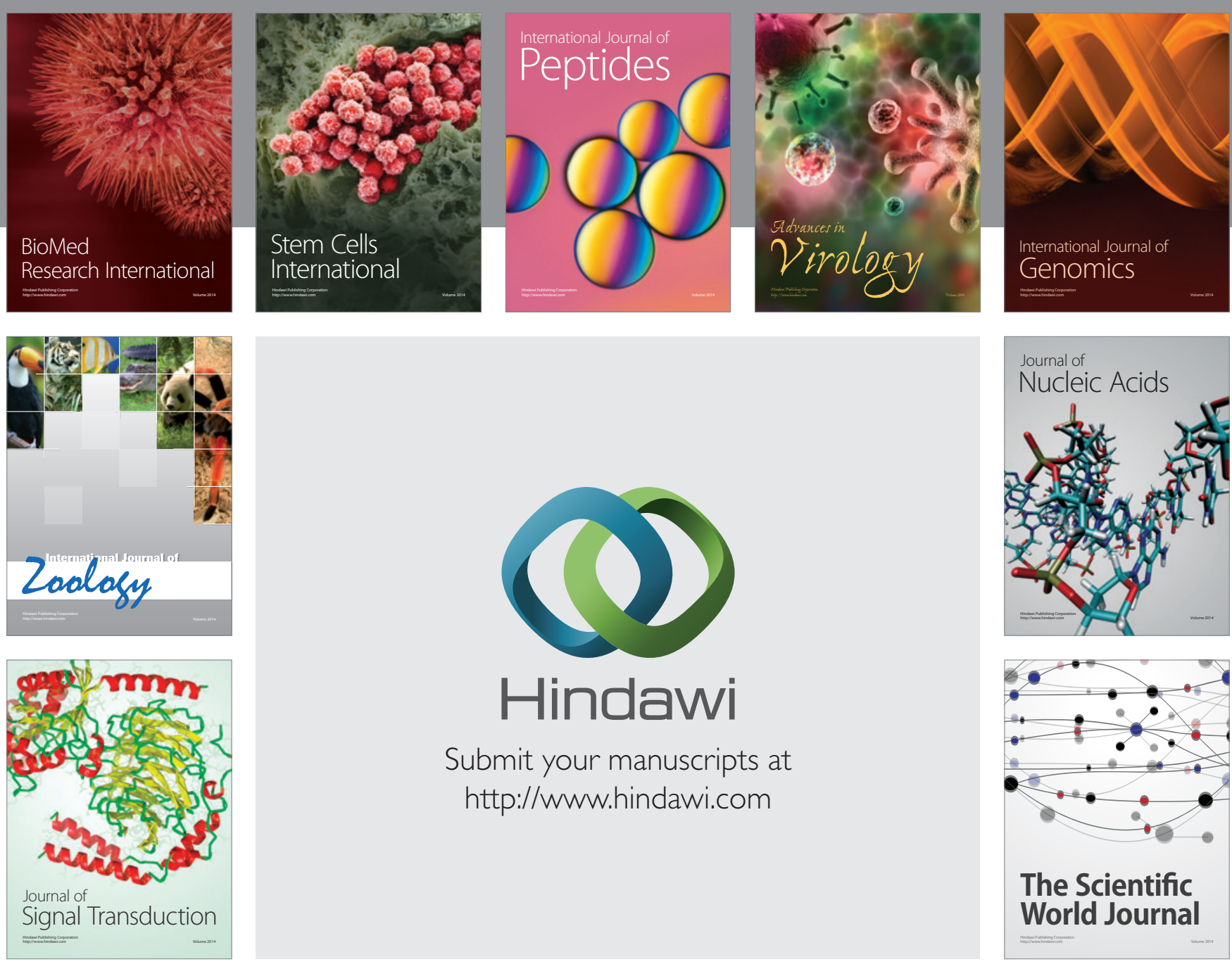

Submit your manuscripts at

http://www.hindawi.com
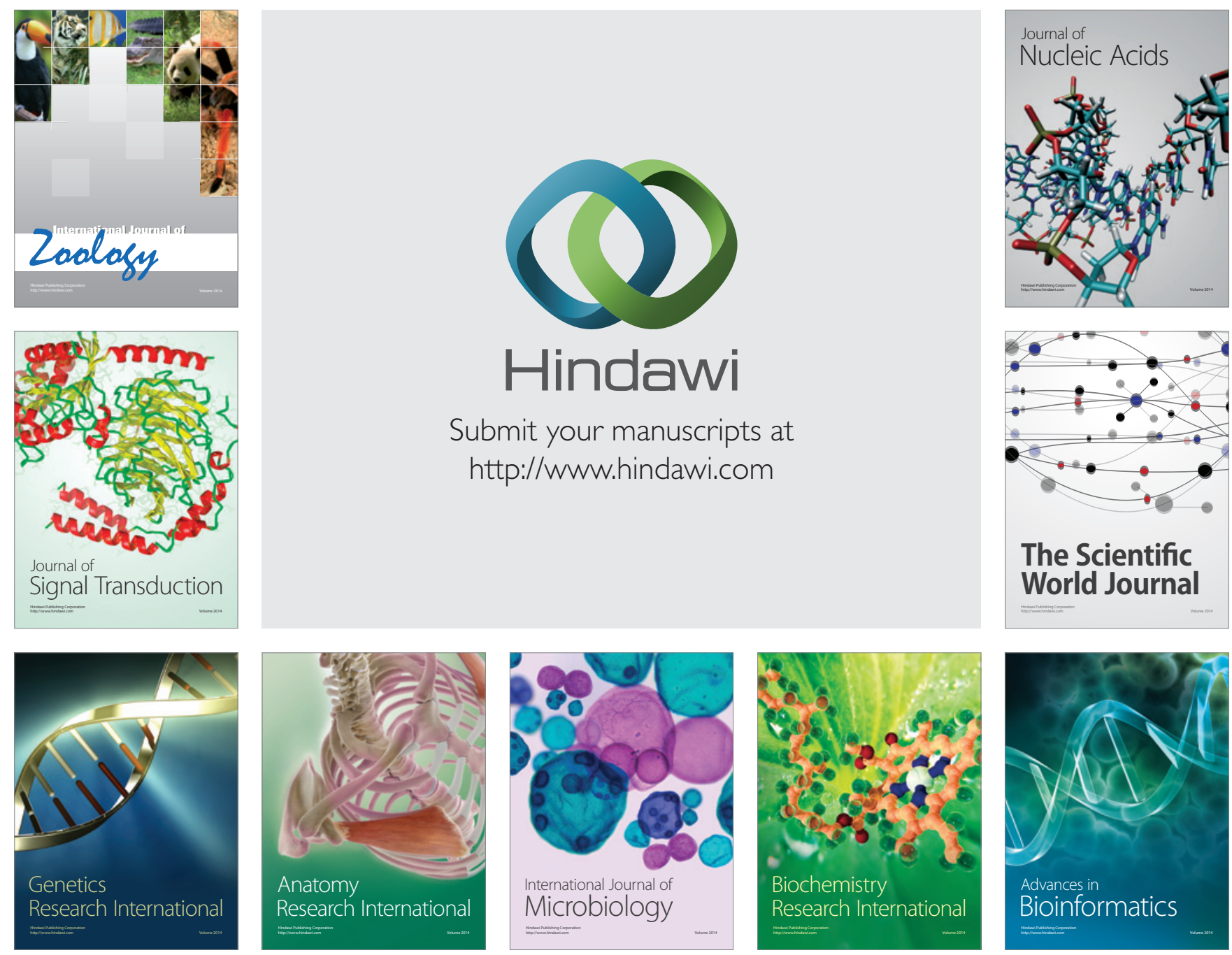

The Scientific World Journal
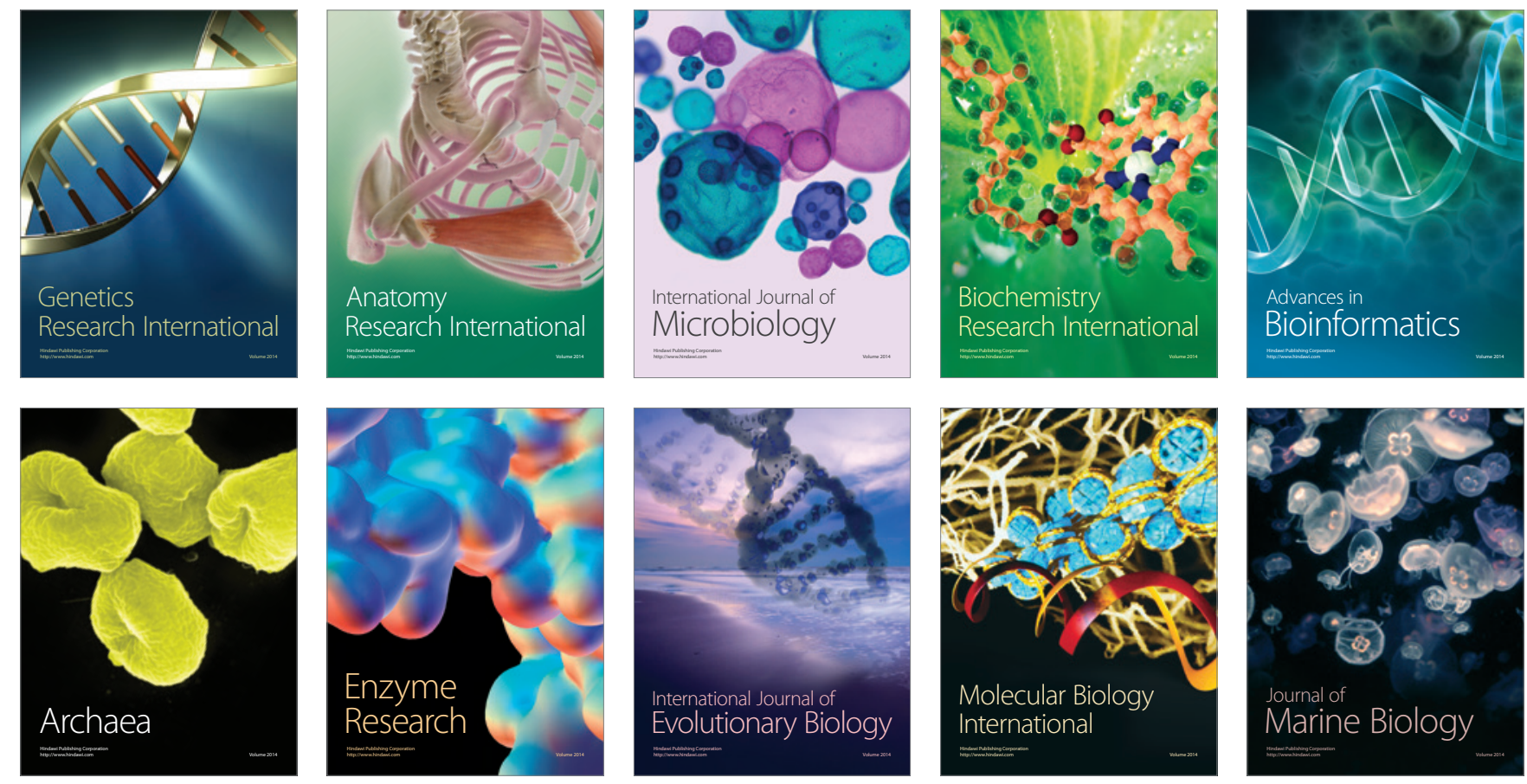